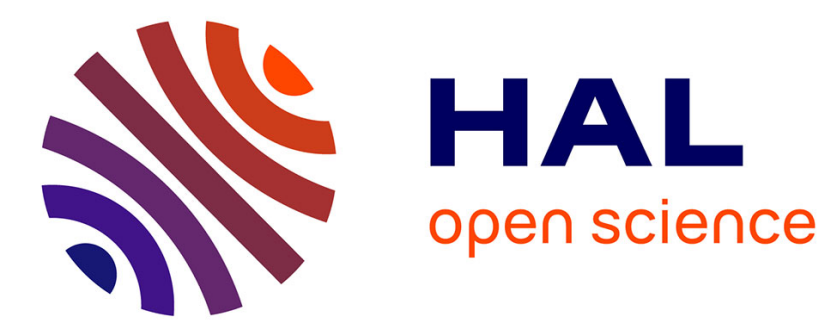

\title{
NUMERICAL SIMULATION OF SPALLATION IN DUCTILE SOLIDS
}

\author{
Z. Wang, F. Huang, S. Yun
}

\section{To cite this version:}

Z. Wang, F. Huang, S. Yun. NUMERICAL SIMULATION OF SPALLATION IN DUCTILE SOLIDS. Journal de Physique IV Proceedings, 1991, 01 (C3), pp.C3-573-C3-576. 10.1051/jp4:1991380 jpa00250525

\section{HAL Id: jpa-00250525 https://hal.science/jpa-00250525}

Submitted on 1 Jan 1991

HAL is a multi-disciplinary open access archive for the deposit and dissemination of scientific research documents, whether they are published or not. The documents may come from teaching and research institutions in France or abroad, or from public or private research centers.
L'archive ouverte pluridisciplinaire HAL, est destinée au dépôt et à la diffusion de documents scientifiques de niveau recherche, publiés ou non, émanant des établissements d'enseignement et de recherche français ou étrangers, des laboratoires publics ou privés. 


\title{
NUMERICAL SIMULATION OF SPALLATION IN DUCTILE SOLIDS
}

\author{
$\mathrm{Z}$. WANG, $\mathrm{F}$. HUANG and $\mathrm{S}$. YUN \\ Mechanics Engineering Department, Beijing Institute of \\ Technology, P.O. Box 327, Beijing 100081, China
}

\begin{abstract}
Un modèle de rupture dynamique pour matériaux ductiles est développé dans cette communication. Le modèle proposé est basé sur la nucléation et la croissance de vides. Pendant la déformation, l'écrouissage, l'influence de la vitesse de déformation et les effets d'inertie sont pris en compte. Ce modèle de rupture est introduit dans un code hydrodynamique pour simuler les premières réflexions de contrainte lors de l'écaillage. Un bon accord est obtenu entre les résultats numériques et expérimentaux.
\end{abstract}

\begin{abstract}
In this paper a dynamic fracture model in ductile solids under the application of a mean tensile stress is developed. The proposed model considers void nucleation and growth as part of the failure process under dynamic loading conditions. In the evolution of distention, work-hardening, rate-dependent contribution and inertial effects are considered. The failure model proposed in the present paper is incorporated in a hydrodynamic computer code, to simulate the first few stress reverberations in the target as it spalls. Fair agreement between computed and experimental results is abtained.
\end{abstract}

\section{Introduction}

A mathematical model of ductile hole growth under the application of a mean tensile stress is developed by Johnson ${ }^{[1]}$. In his model, the nucleation of voids and work-hardening isn't considered. Inertial effects are neglected. Many experiments of dynamic fracture in ductile solids show that the dynamic ductile fracture process is nucleation, growth and coalescence of voids ${ }^{[2,3]}$. The idealization adopted by Chu and Needleman ${ }^{\text {[4] }}$, that void nucleation follows a normal distribution about some mean stress, was employed in the present study. We, with perturbation methods, solved a high nonlinear second-order differential equation and obtained a evolution of distention $\alpha$ in which work-hardening, rate-dependent and inertial effects were considered. The model shows that in primary duration of voids growth inertial resists its growth. As an application of the model, we modeled two spallation processes under a one-dimensional strain impact condition. The results of simulations and experiments are agreement well.

\section{Evolution of the distention $\alpha$}

Based on the Johnson's method, a new evolution of the distention $\alpha$ has been obtained. With some calculation, Johnson gained an equation describing $\alpha$ :

$$
\tau^{2} Y_{0} Q(\ddot{\alpha}, \dot{\alpha}, \alpha)=\alpha\left(P-P_{g}\right)-2 \int_{a}^{b} \frac{\Delta s}{r} d r
$$

where $Y_{0}$ is the yield stress of the solid and

$$
\tau^{2} \equiv \frac{\rho a_{\theta}^{2}}{3 Y_{0}\left(\alpha_{0}-1\right)^{\frac{2}{3}}}
$$




$$
Q(\ddot{\alpha}, \dot{\alpha}, \alpha) \equiv-\alpha\left[(\alpha-1)^{-\frac{1}{3}}-\alpha^{-\frac{1}{3}}\right]+\frac{1}{6} \dot{\alpha}^{2}\left[(\alpha-1)^{-\frac{4}{3}}-\alpha^{-\frac{4}{3}}\right]
$$

$P$ is an externally applied tensile pressure, $P_{g}$ is the internal pressure of void

$$
\Delta S=\sigma_{\gamma}-\sigma_{\theta}= \pm Y_{0}+\eta \dot{\gamma}^{p}
$$

where $\sigma_{\gamma}$ and $\sigma_{\theta}$ are the radical and circumferential deviatonic stresses, $\eta$ is the material viscosity, $\dot{\gamma}^{p}$ is the plastic shear strain rate.

We use following relation ${ }^{[6]}$ :

$$
\Delta S=\sigma_{r}-\sigma_{\theta}=Y_{0}\left(1+\frac{\varepsilon^{p}}{\varepsilon_{0}}\right)^{n}+\eta \dot{\gamma}^{p}
$$

where $\mathrm{n}$ is the strain hardening exponent, $\varepsilon_{0}$ is a strain parameter, $\varepsilon^{p}$ is effective plastic strain. Substitution of Eq.(5) into Eq.(1) gives

$$
\tau^{2} \ddot{\alpha}+\tau^{2} a_{1}(\alpha)(\dot{\alpha})^{2}+a_{2}(\alpha) \dot{\alpha}+a_{3}(\alpha)=0
$$

where

$$
\begin{aligned}
a_{1}(\alpha) & =-\frac{1}{6(\alpha-1)}\left[1+\left(\frac{\alpha-1}{\alpha}\right)^{\frac{1}{3}}\right]\left[1+\left(\frac{\alpha-1}{\alpha}\right)^{\frac{2}{3}}\right] \\
a_{2}(\alpha) & =\frac{\eta}{Y_{0}} \frac{1}{\left(\alpha_{0}-1\right)^{\frac{1}{3}}} \frac{1}{1-\left(\frac{\alpha-1}{\alpha}\right)^{\frac{1}{3}}} \\
a_{3}(\alpha) & =\frac{(\alpha-1)^{\frac{1}{3}}}{1-\left(\frac{\alpha-1}{\alpha}\right)^{\frac{1}{3}}}\left\{\frac{P-P_{\alpha}}{Y_{0}}+\frac{2}{3 n \varepsilon_{0}^{n}}\left(\frac{\alpha-\alpha_{0}}{\alpha-1}\right)^{n}\left[\left(\frac{\alpha-1}{\alpha}\right)^{n}-1\right]\right. \\
& \left.+\frac{2 n}{3(n-1) \varepsilon_{0}^{n-1}}\left(\frac{\alpha-\alpha_{0}}{\alpha-1}\right)^{n-1}\left[\left(\frac{\alpha-1}{\alpha}\right)^{n-1}-1\right]\right\}
\end{aligned}
$$

Let $\dot{\alpha}=y$

Eq.(6) becomes

$$
\tau^{2} y \frac{d y}{d \alpha}+\tau^{2} a_{1}(\alpha) y^{2}+a_{2}(\alpha) y+a_{3}(\alpha)=0
$$

where $\tau^{2}$ is a small quantity. Given initial condition

$$
y\left(\alpha_{0}\right)=y_{0}
$$

Using perturbation method, we finally obtained a solution:

$$
y(\alpha, \varepsilon)=y^{\prime}(\alpha)+u(\zeta)
$$

where

$$
y^{\prime}(\alpha)=-\frac{a_{3}(\alpha)}{a_{2}(\alpha)}
$$




$$
\begin{aligned}
& u(\zeta)=c e^{-\left[\frac{u(\Omega)}{y^{I}\left(\alpha_{0}\right)}+o_{2}\left(\alpha_{0}\right) t\right]} \\
& \zeta=\frac{\alpha-\alpha_{0}}{\varepsilon} \\
& c=\left[y_{0}-y^{I}\left(\alpha_{0}\right)\right] e^{\left[\frac{y_{0}}{y^{I}\left(\alpha_{0}\right)}-1\right]}
\end{aligned}
$$

Porosity rate $\dot{\Phi}$ is given by

$$
\dot{\Phi}=\dot{\Phi}_{\text {nucleation }}+\dot{\Phi}_{\text {growth }}
$$

where $\dot{\Phi}_{\text {nucleation }}$ is the contribution from the nucleation of voids, $\dot{\Phi}_{\text {growth }}$ is the contribution from the growth of existing voids. Here there is

$$
\Phi_{\text {growth }}=\frac{\alpha-1}{\alpha}
$$

Chu and Needleman ${ }^{[4]}$ suggested the following model for nucleation rate:

$$
\begin{aligned}
& \dot{\Phi}_{n \text { wileation }}=A\left(\dot{\sigma}_{m}+\frac{1}{3} \dot{\sigma}_{k k}\right)+B \dot{\varepsilon}_{M}^{p} \\
& A=\left\{\begin{array}{c}
\frac{f_{n}}{s_{n} \sqrt{2 \pi}} \exp \left[-\frac{1}{2}\left(\frac{\sigma_{m}+\frac{1}{3} \sigma_{k k}-\sigma_{n}}{s_{n}}\right)^{2}\right] \\
0 \quad \sigma_{m}+\frac{1}{3} \sigma_{k k}-\sigma_{n}>0
\end{array}\right.
\end{aligned}
$$

where $\sigma_{m}$ is the microscopic effective stress in the matrix material, $\frac{1}{3} \sigma_{k k}$ is the microscopic mean stress, $\ddot{\varepsilon}_{M}^{p}$ is the microscopic effective strain platic rate. In the present study to describe spallation type failure, we neglected the nucleation rate due to plastic strain, $\mathrm{B}=0$. The nucleation model parameters are $f_{n}, s_{n}, \sigma_{n}$.

\section{Comparison between simulations and experiments}

The proposed new model was used to simulate two plate impact tests. One is the test in Mader's paper ${ }^{[51}$ in which a 3.175-mm aluminum flyer plate impacts a $12.7-\mathrm{mm}$ aluminum target at a velocity of $1.0 \mathrm{~mm} / \mu \mathrm{s}$. Another is ours in which a $5.28-\mathrm{mm}$ LY12 aluminum flyer plate impacts a $9.92-\mathrm{mm}$ LY12 aluminum target at $0.35-\mathrm{mm} / \mu \mathrm{s}$. Mesured response for spall fracture in LY12 aluminum compared with simulation is shown in Fig.2. Postshot photomicrographic observation of the residual porosity compared with the computed results is shown in Fig.3. Comparison of model simulation with the experimental velocity vs. time plot for aluminum (Mader's experiment ${ }^{\text {[S] }}$ ) is shown in Fig.1.

\section{Conclusions}

The spall failure was described by the dynamic ductile fracture model in this work. The model was based on microvoid nucleation and growth in materials due to a mean tensile stress. Work-hardening, rate-dependent contribution and inertial effects were added to the model. Simulations with the model were in agreement with the experimental results well. 


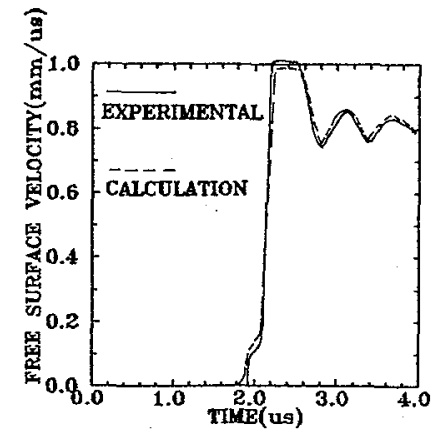

Fig.1 Comparison of model simulation with the experimental velocity vs. time plot for aluminum

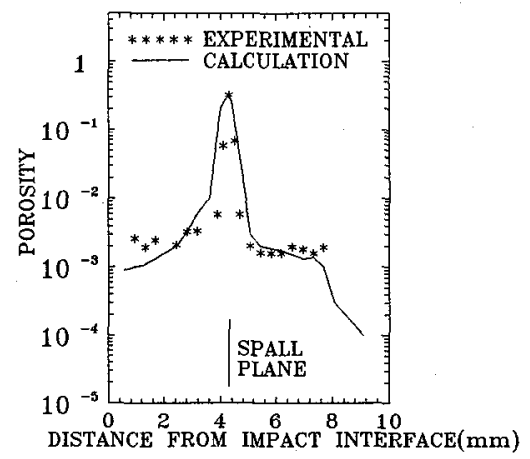

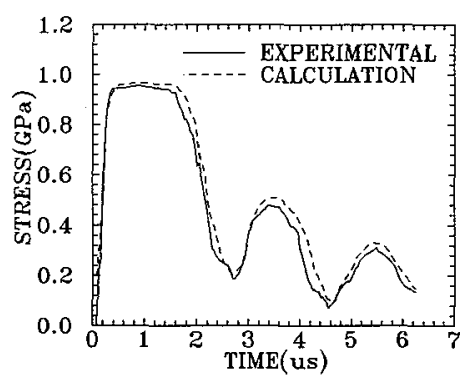

Fig.2 Comparison of stress record from manganin gage in PMMA behind LY12 aluminum with computed stress

Fig.3 Comparison of calculation (solid line) and measured (data points) postimpact porosity in LY12 aliminum sample

\section{References}

[1] Johnson, J. N., J. Appl. Phys. Vol.52, 2812(1981).

[2] Curran,D.R., Seaman,L. and Shockey, D.A., Physics Reports, Vol. 147, Nos.5 \& 6, 253-388 (1987).

[3] Meyers, Marc Andre and Aimone, Calherine Taylor, Progress in Material Sciences, Vol. 28,1-96 (1983).

[4] Chu,C.C., Needleman, A.,J, Engr. Mat. Tech., Vol 102, 249(1980).

[5] Mader, C.L., LA-3678 (1967).

[6] Regazzoni,G., Johnson, J.N. and Follansbee, P.S., J. Appl. Mech., Vol 53, 519 (1986). 